\title{
Optimizing the properties of hybrids based on graphene oxide for carbon dioxide capture
}

\author{
Yating Yea , L. Vega Martín ${ }^{\mathrm{a}}$, M. J. Sánchez Monteroa, b, c; D. López-Díaz, d,M.M. \\ Velázquez ${ }^{\mathrm{a}, \mathrm{b}, \mathrm{c}} ;$ M.D. Merchán ${ }^{\mathrm{a}, \mathrm{b}, \mathrm{c}^{*}}$ \\ ${ }^{a}$ Departamento de Química Física, Facultad de Ciencias Quimicas, Universidad de \\ Salamanca, E-37008 Salamanca, Spain \\ ${ }^{\mathrm{b}}$ Grupo de Nanotecnología, Universidad de Salamanca, E37008 Salamanca, Spain \\ 'Laboratorio de Nanoelectrónica y Nanomateriales, USAL-NANOLAB, Universidad \\ de Salamanca, E37008 Salamanca, Spain \\ ${ }^{\mathrm{d}}$ Departamento de Química Analítica, Química Física e Ingeniería Química, Universidad de
}

Alcalá. 28871 Alcalá de Henares, Madrid, Spain.

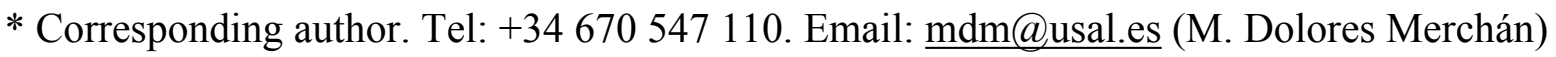


SECTION 1. Characterization of GO/PANI composites and GO/ACF hydrogels

XPS Analysis

Table S1. Percentages of different elements obtained from XPS measurements.

\begin{tabular}{|l|c|c|c|c|c|c|c|c|}
\hline \multicolumn{1}{|c|}{ Sample } & $\mathbf{\%} \mathbf{C}$ & $\mathbf{\% O}$ & $\mathbf{\% N}$ & $\mathbf{\% S}$ & $\mathbf{\% K}$ & $\mathbf{C / O}$ & $\mathbf{\% ~ C s p ~}^{\mathbf{2}}$ & $\mathbf{\% ~ C s p ~}^{\mathbf{3}}$ \\
\hline \hline GO12 & 68 & 29 & 0.8 & 0 & 0 & 2.3 & 44 & 56 \\
\hline GO12PANI* & 87.6 & 6 & 6.4 & 0 & 0 & 14.3 & 64 & 36 \\
\hline GO12PANIK & 84.8 & 6.8 & 7.5 & 0 & 0.9 & 12.5 & 63 & 37 \\
\hline GO24 & 41.4 & 48.7 & 0 & 9.9 & 0 & 0.9 & 60.3 & 39.7 \\
\hline GO24H & 86.3 & 15.1 & 0 & 0.6 & 0 & 6.6 & 51.5 & 48.5 \\
\hline GO24FH73 & 76.9 & 21.1 & 0 & 2.0 & 0 & 3.7 & 53.2 & 46.8 \\
\hline GO24FH55 & 79.6 & 18.9 & 0 & 1.6 & 0 & 4.2 & 55.3 & 44.7 \\
\hline GOFH55CPy & 78.1 & 19.1 & 1.1 & 1.7 & 0 & 4.1 & 55.4 & 44.6 \\
\hline GPFH37 & 80.8 & 17.8 & 0 & 1.4 & 0 & 4.5 & 55.3 & 44.7 \\
\hline ACF & 91.1 & 8.9 & 0 & 0 & 0 & 10.3 & 67.2 & 32.8 \\
\hline
\end{tabular}

(*) Data taken from ref. 1 

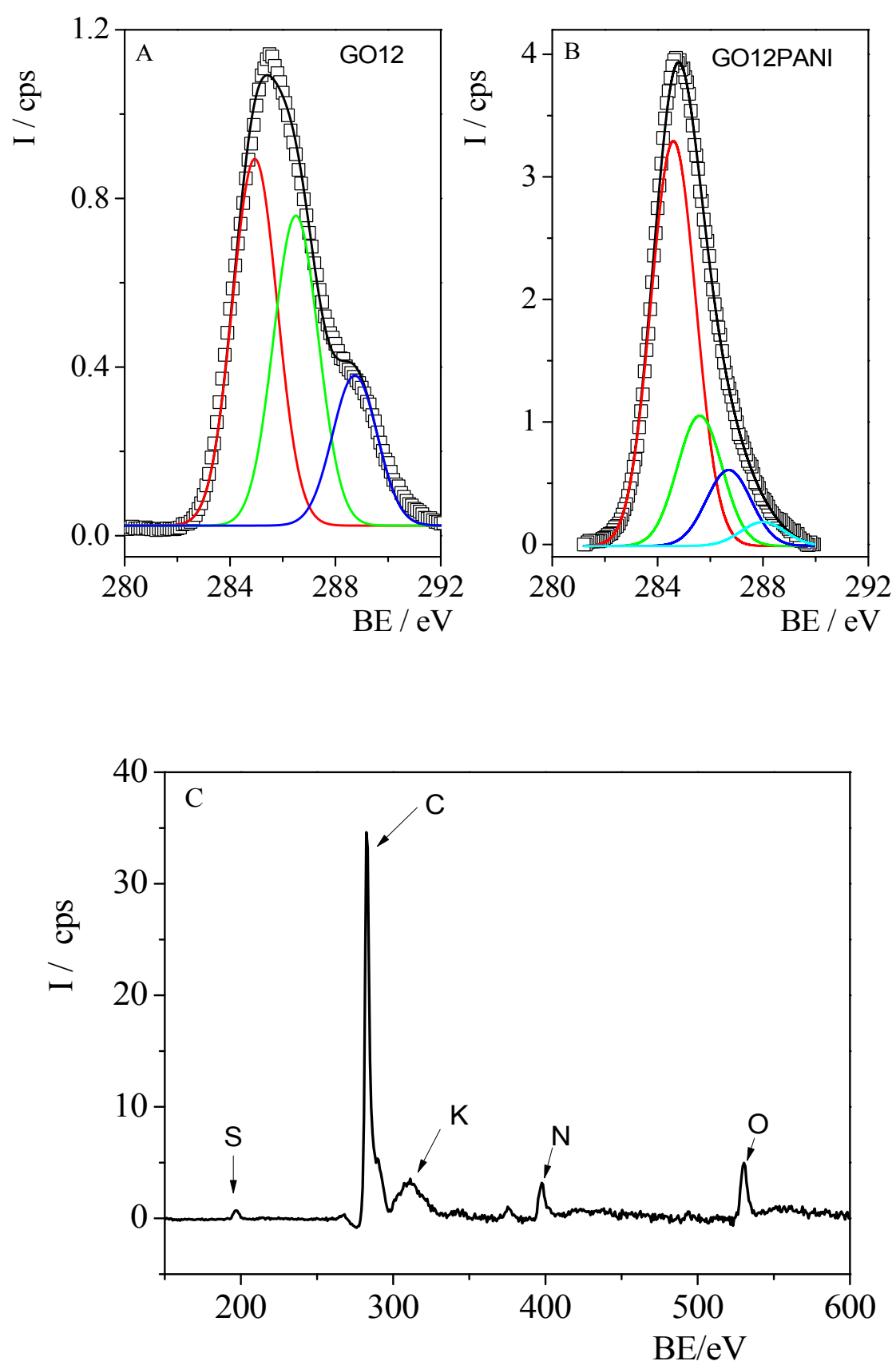

Figure S1: X-ray photoelectron spectra of C1s core level of A) GO12 and B) GO12PANI. C) Survey of XPS of GO12PANIK. 

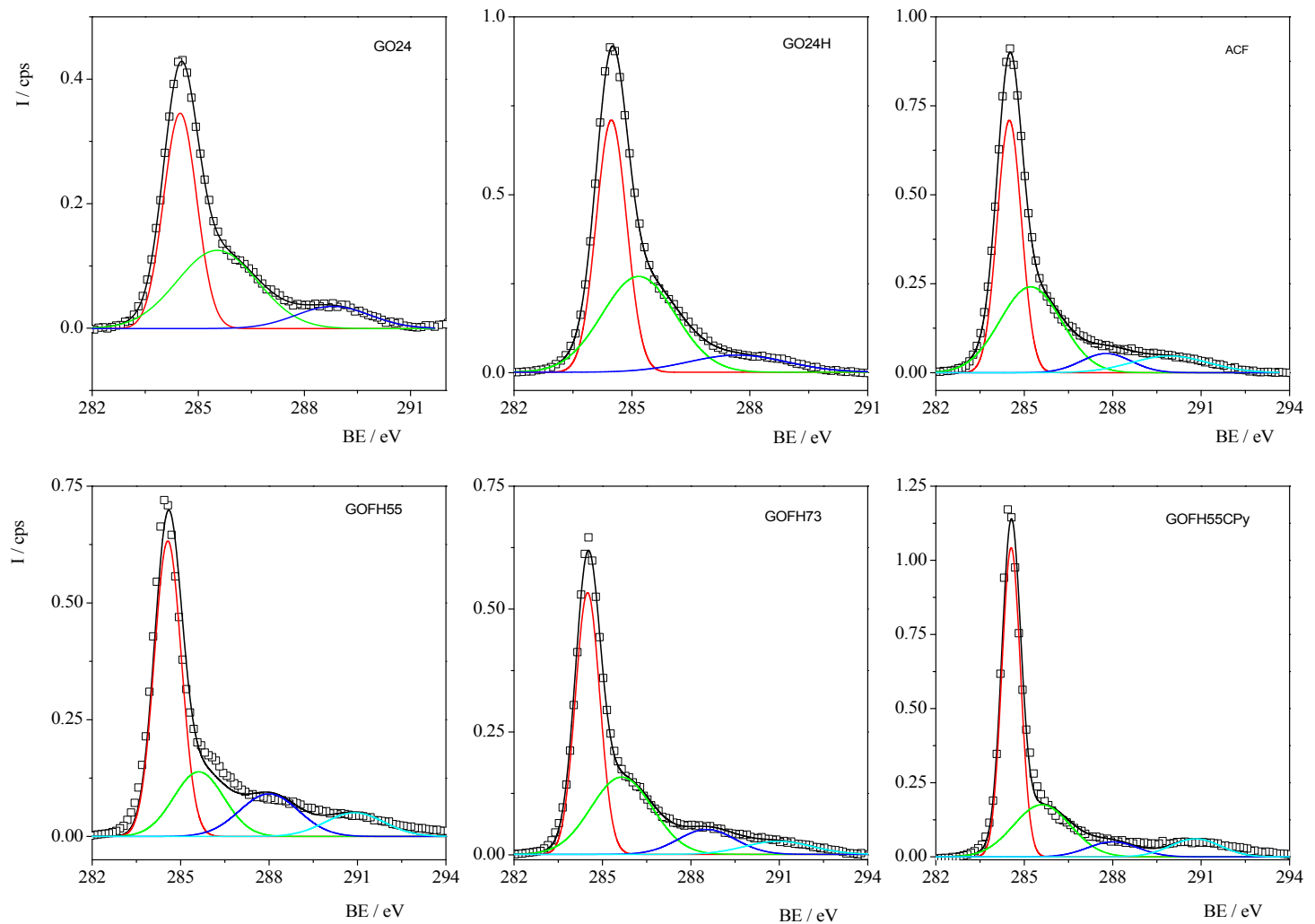

Figure S2: X-ray photoelectron spectra of $\mathrm{C} 1 \mathrm{~s}$ core level of $\mathrm{GO} 24, \mathrm{GO} 24 \mathrm{H}$. Activated carbon fibers and hydrothermal composites of GO24 and carbon fibers GO/Carbon Fibers ratio of: 50/50. GOFH55; 70/30. GOFH73 and GO/Carbon fibers ratio of 50/50 in cethyl pyridinium chloride.

\section{XRD Analysis}

Table S2. Interlayer distance calculated by the Bragg's law (002) peak. Analysis of the grain size, $C$ by the XDR (100) peak by Scherrer's equation: $C=0.9 \lambda /(\beta \cos \theta) . \lambda=1.5405 \AA$; $\beta=$ half weight width in radians; $\theta$ is the diffraction angle. GO24 doesn't show (100) reflection.

\begin{tabular}{|c|c|c|c|c|c|}
\hline \multirow[b]{2}{*}{ Sample } & \multicolumn{2}{|c|}{ Bragg's Law } & \multicolumn{3}{|c|}{ Scherrer's equation } \\
\hline & $2 \theta /{ }^{\circ}$ & (d/nm & $2 \theta /{ }^{\circ}$ & $\bar{\beta} / /^{\mathbf{o}}$ & 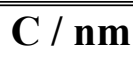 \\
\hline GO12 & 25.5 & 0.35 & 42.23 & 0.299 & 28.48 \\
\hline GO12PANI & 24.7 & 0.36 & 43.05 & 0.661 & 12.92 \\
\hline GO12PANIK & 25.9 & 0.34 & 43.41 & 0.936 & 9.14 \\
\hline GO24 & 24.0 & 0.37 & - & - & - \\
\hline $\mathrm{GO} 24 \mathrm{H}$ & 24,6 & 0.36 & 42.61 & 0.83 & 10.30 \\
\hline GO24FH73 & 24,5 & 0.36 & 42.68 & 1.51 & 5.65 \\
\hline GO24FH55 & 24,5 & 0.36 & 42.53 & 1.53 & 5.57 \\
\hline GOFH55CPy & 24,4 & 0.36 & 42.80 & 1.78 & 4.79 \\
\hline GOFH37 & 24,2 & 0.37 & 43.56 & 1.71 & 5.00 \\
\hline $\mathrm{ACF}$ & - & - & 43.76 & 2.12 & 4.03 \\
\hline
\end{tabular}




\section{Raman Analysis}
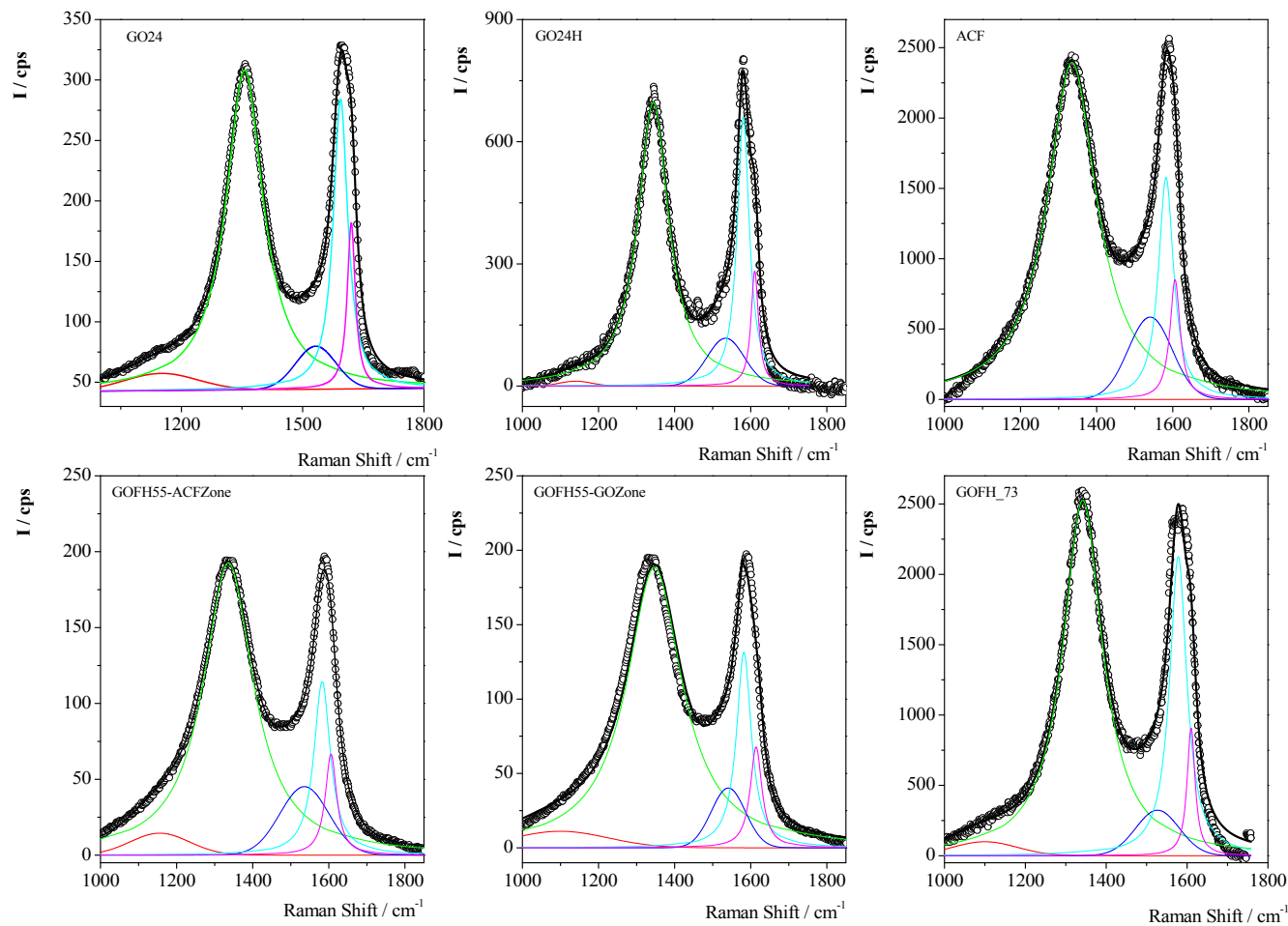

Figure S3: Deconvolution of the first order Raman spectrum of GO24, GO24H, GOFH73, GO24FH55 and Carbon Fibers.
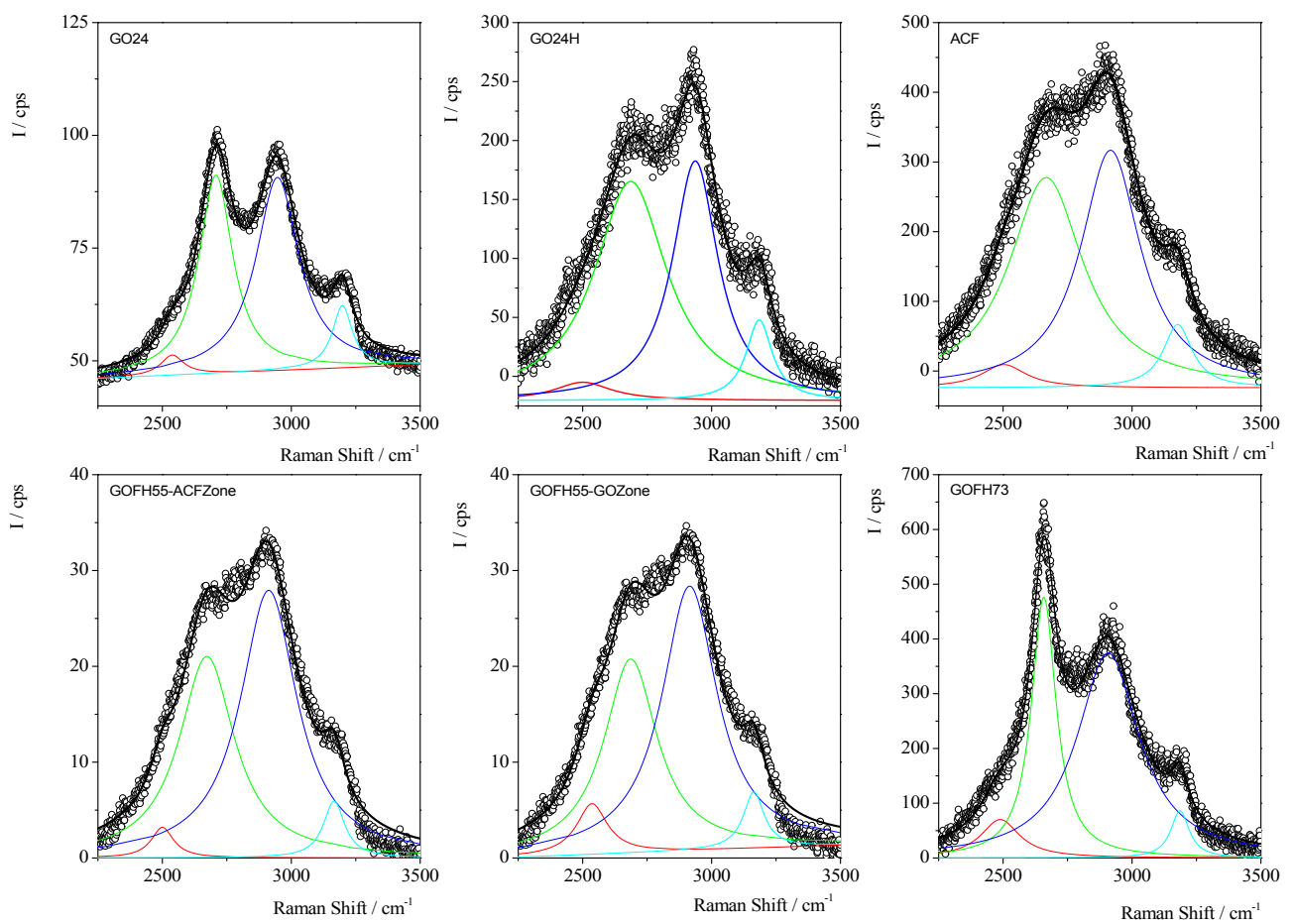

Figure S4: Deconvolution of the second order Raman spectrum of GO24, GO24H, GOFH73, GO24FH55 and Carbon Fibers. 
Table S3: Fitting parameters for hydrogels of the first-order Raman spectra

\begin{tabular}{|c|c|c|c|c|c|c|c|c|c|c|c|c|c|c|c|}
\hline \multirow[b]{2}{*}{ Material } & \multicolumn{3}{|c|}{$D^{*}$ (Gauss) } & \multicolumn{3}{|c|}{ D(Ps-Voight) } & \multicolumn{3}{|c|}{$D^{\prime \prime}$ (Gauss) } & \multicolumn{3}{|c|}{ G (Ps-Voight) } & \multicolumn{3}{|c|}{ D'( Ps-Voight) } \\
\hline & $\mathbf{x}_{\mathrm{c}}\left(\mathrm{cm}^{-1}\right)$ & $\mathrm{w}\left(\mathrm{cm}^{-1}\right)$ & $A(\%)$ & $\mathrm{x}_{\mathrm{c}}\left(\mathrm{cm}^{-1}\right)$ & $\mathrm{w}\left(\mathrm{cm}^{-1}\right)$ & $\mathbf{A}(\%)$ & $\mathrm{x}_{\mathrm{c}}\left(\mathrm{cm}^{-1}\right)$ & $\mathrm{w}\left(\mathrm{cm}^{-1}\right)$ & A (\%) & $\mathrm{x}_{\mathrm{c}}\left(\mathrm{cm}^{-1}\right)$ & $\mathbf{w}\left(\mathrm{cm}^{-1}\right)$ & A (\%) & $x_{c}\left(\mathrm{~cm}^{-1}\right)$ & $\mathbf{w}\left(\mathrm{cm}^{-1}\right)$ & $A(\%)$ \\
\hline GO24 & 1150 & 213 & 4 & 1356 & 112 & 61 & 1533 & 117 & 6 & 1594 & 44 & 22 & 1620 & 24 & 7 \\
\hline $\mathrm{GO} 24 \mathrm{H}$ & 1140 & 84 & 1 & 1344 & 99 & 62 & 1534 & 98 & 8 & 1580 & 39 & 23 & 1610 & 24 & 6 \\
\hline GO24FH73 & 1100 & 159 & 3 & 1342 & 119 & 64 & 1527 & 108 & 6 & 1578 & 51 & 23 & 1610 & 24 & 5 \\
\hline GO24FH55-F & 1156 & 156 & 4 & 1336 & 159 & 67 & 1536 & 129 & 10 & 1583 & 53 & 13 & 1606 & 36 & 5 \\
\hline GO24FH55-GO & 1100 & 249 & 5 & 1347 & 176 & 70 & 1541 & 90 & 6 & 1582 & 47 & 13 & 1614 & 37 & 5 \\
\hline GO24FH37 & 1100 & 265 & 5 & 1345 & 128 & 64 & 1530 & 107 & 7 & 1585 & 51 & 17 & 1609 & 31 & 6 \\
\hline $\mathrm{ACF}$ & 1100 & 52 & $\sim 0$ & 1335 & 159 & 71 & 1541 & 136 & 10 & 1582 & 48 & 14 & 1606 & 32 & 5 \\
\hline
\end{tabular}

Table S4: Relative intensity for Hydrogels of some Raman bands.

\begin{tabular}{|l|c|c|}
\hline Material & $\mathbf{A}_{\mathbf{D}} / \mathbf{A}_{\mathbf{D}}$ & $\mathbf{I}_{\mathbf{D}} / \mathbf{I}_{\mathbf{G}}$ \\
\hline GO24 & 0.11 & 1.10 \\
\hline GO24H & 0.10 & 1.35 \\
\hline GO24FH73 & 0.07 & 1.19 \\
\hline GO24FH55-ACF zone & 0.08 & 1.69 \\
\hline GO24FH55-GO zone & 0.14 & 1.43 \\
\hline GO24FH37 & 0.09 & 1.45 \\
\hline ACF & 0.07 & 1.52 \\
\hline
\end{tabular}


Table S5: Fitting parameters for different samples of the second-order Raman spectra

\begin{tabular}{|c|c|c|c|c|c|c|c|c|c|c|c|c|}
\hline \multirow{2}{*}{ Material } & \multicolumn{3}{|c|}{ G* (Lorentz) } & \multicolumn{3}{|c|}{ 2D(Lorentz) } & \multicolumn{3}{|c|}{ D+D'(Lorentz) } & \multicolumn{3}{|c|}{ 2D' (Lorentz) } \\
\hline & $x_{c}\left(\mathrm{~cm}^{-1}\right)$ & $w\left(\mathrm{~cm}^{-1}\right)$ & A (\%) & $x_{c}\left(\mathrm{~cm}^{-1}\right)$ & $w\left(\mathrm{~cm}^{-1}\right)$ & A (\%) & $x_{c}\left(\mathrm{~cm}^{-1}\right)$ & $\mathrm{w}\left(\mathrm{cm}^{-1}\right)$ & A (\%) & $\mathrm{x}_{\mathrm{c}}\left(\mathrm{cm}^{-1}\right)$ & $w\left(\mathrm{~cm}^{-1}\right)$ & A (\%) \\
\hline $\mathrm{GO} 24$ & 2538 & 109 & 3 & 2708 & 160 & 40 & 2946 & 201 & 50 & 3198 & 94 & 7 \\
\hline $\mathrm{GO} 24 \mathrm{H}$ & 2500 & 271 & 4 & 2686 & 342 & 53 & 2937 & 215 & 36 & 3185 & 124 & 7 \\
\hline GO24FH73 & 2489 & 183 & 7 & 2658 & 117 & 30 & 2907 & 293 & 59 & 3186 & 87 & 4 \\
\hline GO24FH55-F & 2500 & 105 & 2 & 2673 & 261 & 39 & 2913 & 268 & 54 & 3166 & 100 & 4 \\
\hline GO24FH55-GO & 2536 & 145 & 6 & 2686 & 252 & 37 & 2915 & 260 & 53 & 3.164 & 98 & 4 \\
\hline GO24FH37 & 2563 & 165 & 6 & 2693 & 225 & 33 & 2926 & 242 & 54 & 3178 & 109 & 6 \\
\hline Carbon Fibers & 2525 & 74 & 1 & 2670 & 337 & 53 & 2924 & 259 & 43 & 3172 & 81 & 3 \\
\hline
\end{tabular}

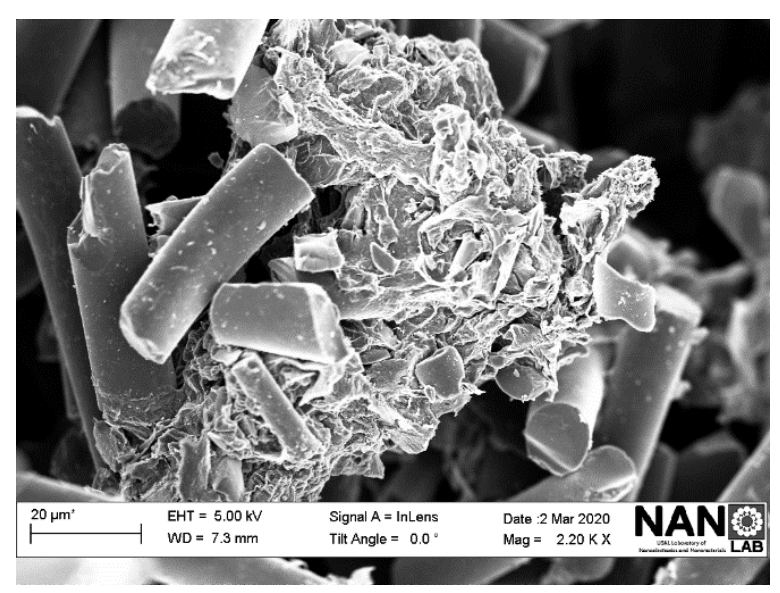

Figure S5: SEM image of GOFH55CPy 
SECTION 2. Adsorption isotherms

\section{Micropore Volume analysis (Dubinin-Radushkevich model)}

The micropore volume was calculated attending to Dubinin-Radushkevich model, eq. S1.

$$
\log V=\log V_{0}-\left[\frac{R T}{E_{0}}\right]^{2}\left[\log \left(\frac{p^{0}}{p}\right)\right]^{2}
$$

In eq. $\mathrm{S} 1, \mathrm{~V}$ represents the volume of $\mathrm{CO}_{2}$ adsorbed at $\left(\mathrm{cm}^{3} / \mathrm{g} \mathrm{STP}\right)$ at $\mathrm{T}$ and $\mathrm{p} / \mathrm{p} . \mathrm{V}_{\mathrm{o}}$ is the micropore capacity $\left(\mathrm{cm}^{3} / \mathrm{g} \mathrm{STP}\right)$ and $\mathrm{E}_{\mathrm{o}}$ represents the characteristic energy of adsorption. $\mathrm{V}$ is calculated trough $\mathrm{V}=\Delta \mathrm{n} \mathrm{M} / \rho$ where $\Delta \mathrm{n}$ is $\mathrm{CO}_{2}$ adsorbed in $\mathrm{mol} / \mathrm{g}, \mathrm{M}$ is the molar mass and $\rho$ is the density of $\mathrm{CO}_{2}$ at a given temperature. The volume of micropore is expressed as the volume of $\mathrm{CO}_{2}$ condensed in micropores, obtained by the conversion of the experimental data with the density conversion factor, D $\left(\mathrm{cm}^{3}\right.$ liquid $\left./ \mathrm{cm}^{3} \mathrm{STP}\right)$. 
$\mathbf{N}_{2}$ adsorption isotherms

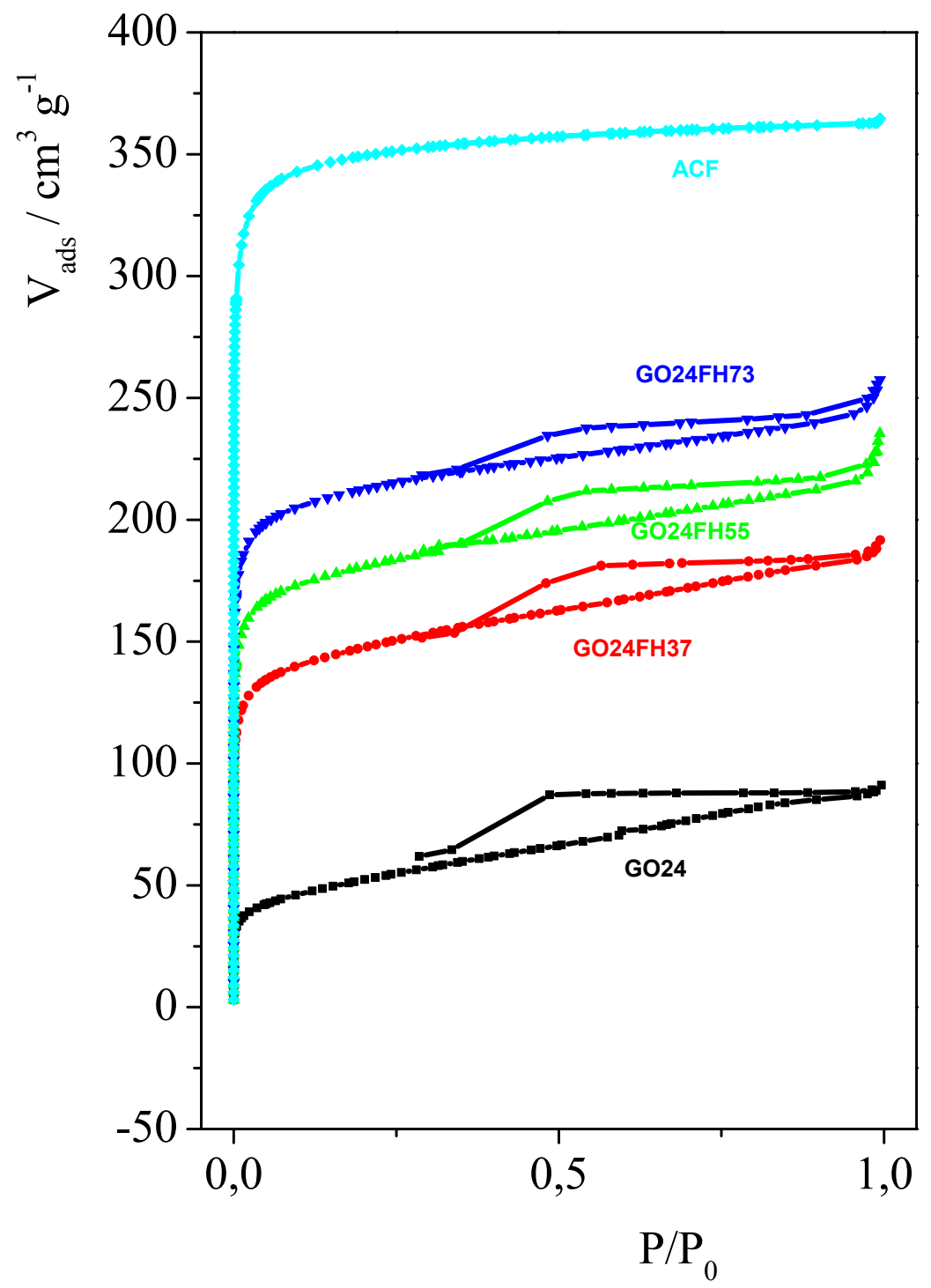

Figure S6: $\mathrm{N}_{2}$ adsorption-desorption isotherm of the GO24/ACF hydrogels, and ACF at 77K. 


\section{Adsorption of $\mathrm{CO}_{2}$}

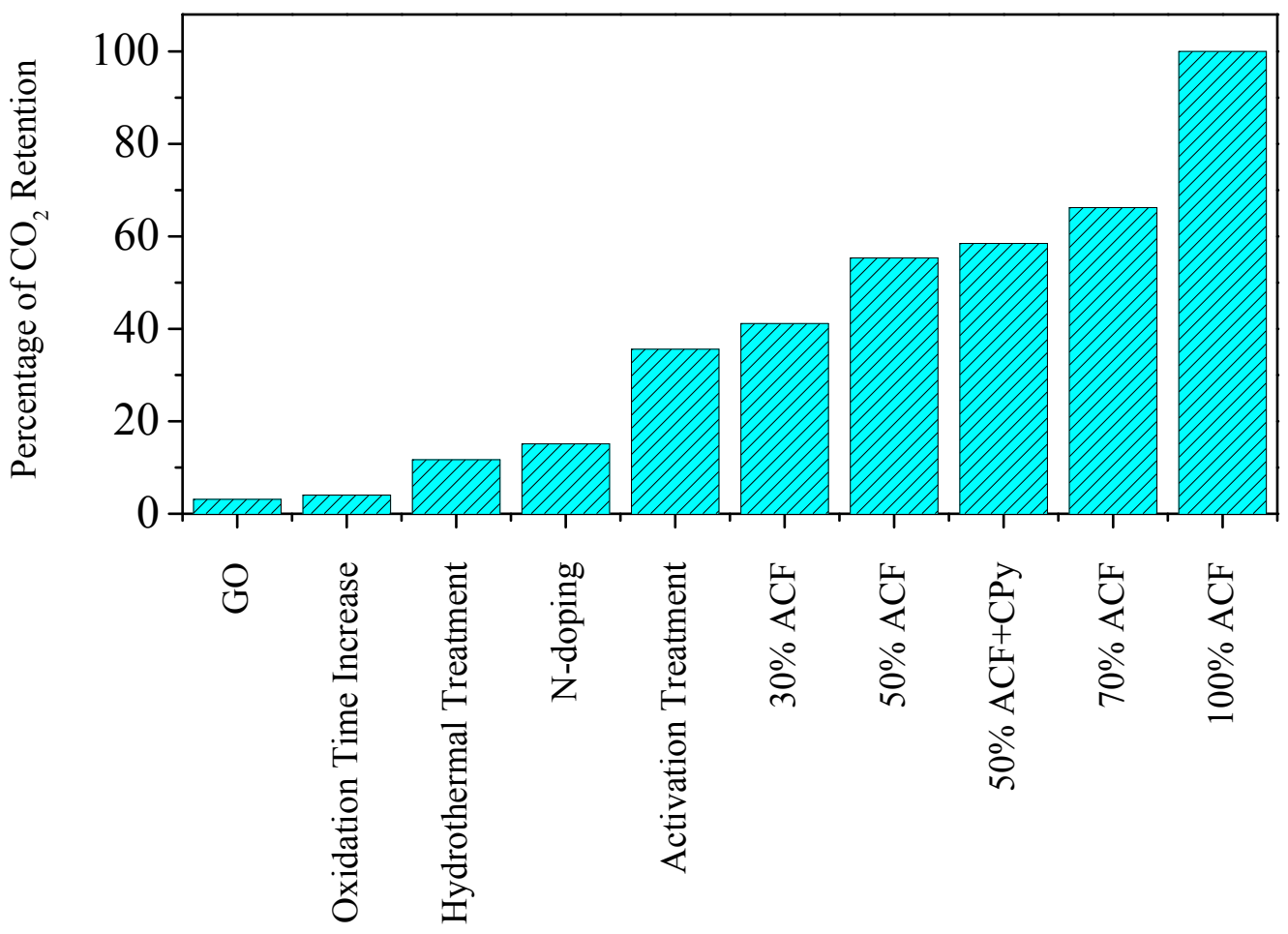

Figure S7: Comparison of the different strategies employed to improve the $\mathrm{CO}_{2}$ retention relative to the $\mathrm{CO}_{2}$ uptake of the ACF at 1 bar. 


\section{Acknowledgment}

The work was financed by European Regional Development Fund, ERDF, and Junta de Castilla y León (SA121P20 and 2020/00325/001). Authors also acknowledge USALNANOLAB for Raman facility. XPS measurements were performed in Servicio de espectroscopia de fotoelectrones de Rayos X de la Universidad de Málaga.

Authors acknowledge financial support from Junta de Castilla y León (2020/00325/001).

Dr. Merchán wishes to thank the time she worked with Prof. Fierro. From him she learned to love the hours in the laboratory and the need for total dedication to obtain the best results. She values and maintains Prof. Fierro's model of meticulousness, patience, rigor and wisdom.

\section{Supporting Information}

SECTION 1: Details about the structural characterization of GO/PANI composites and GO/ACF hydrogels using XPS, XRD and Micro-Raman spectroscopy.

SECTION 2: Adsorption isotherms. Details about the Micropore Volume analysis (DubininRadushkevich model) and $\mathrm{N}_{2}$ adsorption isotherms of the GO24/ACF hydrogels.

SECTION 3: Comparison between the $\mathrm{CO}_{2}$ adsorption capacities at $273 \mathrm{~K}$ and 1 bar of the different composites synthesized in the work. 
TOC

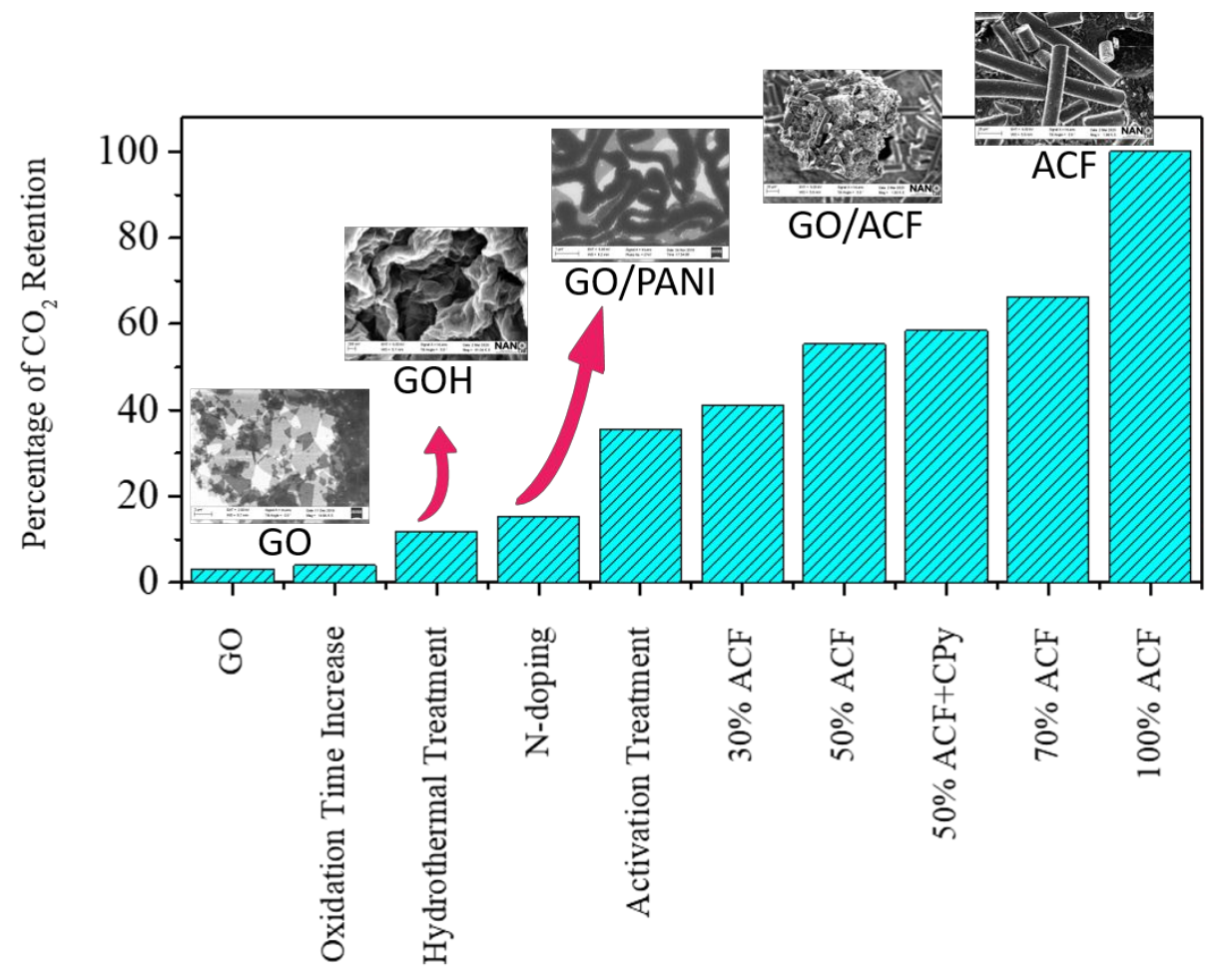

